\title{
Tubular Adenoma of the Breast: A Rare Case Presentation and Review of Literature
}

ISSN: 2578-0379

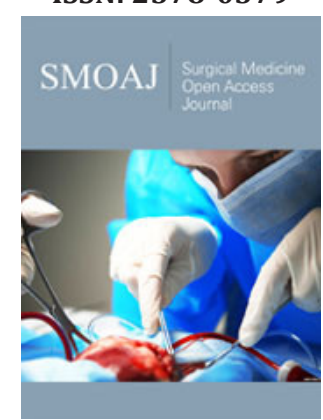

*Corresponding author: Emmanuel Owusu Ofori, Department of Surgery, Cape Coast Teaching Hospital, Ghana

\section{Submission: 些眥 March 23, 2019}

Published: 嶆 March 27, 2019

Volume 2 - Issue 4

How to cite this article: OFORI EO, DAYIE MSC-JK, BIN ALHASSAN BA, AKAKPO K, RAHMAN GA. Tubular Adenoma of the Breast: A Rare Case Presentation and

Review of Literature. Surg Med Open Acc J.2(4). SMOAJ.000541.2019. DOI: $10.31031 /$ SMOAJ.2019.02.000541.

Copyright@ Emmanuel Owusu Ofori, This article is distributed under the terms of the Creative Commons Attribution 4.0 International License, which permits unrestricted use and redistribution provided that the original author and source are credited.

\author{
Emmanuel Owusu Ofori' ${ }^{1 *}$, Makafui S. C-J. K. Đayie ${ }^{1}$, Baba Alhaji Bin Alhassan ${ }^{1}$, \\ Kafui Akakpo², G.A Rahman ${ }^{3}$ \\ ${ }^{1}$ Department of Surgery, Cape Coast Teaching Hospital, Ghana \\ ${ }^{2}$ Department of Pathology, University of Cape Coast School of Medical Sciences and Cape \\ Coast Teaching Hospital, Ghana \\ ${ }^{3}$ Department of Surgery, University of Cape Coast School of Medical Sciences and Cape Coast \\ Teaching Hospital, Ghana
}

\begin{abstract}
Tubular adenomas are a rare breast entity constituting $0.3-1.7 \%$ of all benign tumours first described in 1968 typically affecting women in their reproductive ages (15-49 years). Few cases have been reported in the literature. They are rarely found before menarche or after menopause. Preoperatively, tubular adenomas are difficult to differentiate from fibroadenoma, phyllodes and tubular carcinoma. We report the case of a 25-year-old female who reported to our clinic with 4-month history of painless left breast mass which had not seen any significant changes in size. Histological findings were consistent with tubular adenoma.
\end{abstract}

Keywords: Tubular adenoma; Benign breast tumours; Preoperative diagnosis

\section{Introduction}

A tubular adenoma constitutes $0.3-1.7 \%$ of all breast benign tumours making it a very rare entity [1,2]. Persaud et al [3] first described it in 1968. The first case of tubular adenoma of the breast studied by aspiration cytology and light and electron microscopy was done by Moross et al [4]. Typically, it affects young women in their reproductive ages (15-49 years) rarely before menarche or after menopause [5]. It is interesting to note that few cases have been reported in literature. Tubular adenomas typically affect the upper and outer quadrant of the breast. Comparatively whereas lactating adenomas are strongly associated with pregnancy or oral contraceptive pills (OCPs), tubular adenomas have no such associations [6,7].

It is difficult to distinguish it preoperatively from fibroadenoma, phyllodes, adenosis and tubular carcinoma. Only histology can achieve a definitive diagnosis [5]. Cytology doesn't offer much as it fails to diagnose correctly tubular adenoma [4]. Breast adenomas are subdivided into true adenomas, nipple adenomas and fibroadenomas [8]. True adenomas of the breast are cellular epithelial lesions. They are difficult to distinguish from carcinoma. Electron microscopy shows that adenomas have ultrastructural features like normal breast epithelium. Nipple adenoma is a benign proliferative process of the lactiferous ducts of the nipple. Relatively, nipple adenomas are uncommon. In contributing to the knowledge of understanding the diagnostic challenges especially in a resource limited setting, we report this rare case of a 25-year-old woman with breast tubular adenoma. Breast tubular adenoma has not been associated with an increased risk of breast cancer development [9] hence surgical excision is only necessary for definitive diagnosis [5].

\section{Case Report}

A 25-year-old female trader with no history of cigarette smoking or alcohol ingestion presented to the surgical outpatient department with a 4-month history of painless left breast mass which had not changed in size since it was first noticed. There were no associated nipple discharge or skin changes. Other systemic enquiry was unremarkable. She denied any use of herbal preparation. She also had no risk factors of breast cancer and family history of breast 
cancer or ovarian cancer [9].

Examination revealed a young woman, well-built for age and gender, not pale, anicteric, afebrile and well hydrated. A $2 \mathrm{cmx} 1 \mathrm{~cm}$ firm, well-defined, non-tender, mobile mass with no attachment to skin or underlying muscle was felt. The mass was located in the upper and outer quadrant of the left breast. No regional lymph nodes were palpable. Other systems were normal on examination. An ultrasound scan of her breast made an impression of a left breast fibroadenoma (BIRADS II) of $2 \mathrm{~cm} \times 2 \mathrm{~cm} \times 1 \mathrm{~cm}$ in size.

Patient requested for removal of her breast lump and was subsequently scheduled for an excision biopsy of the left breast mass with histopathology results as follows:

Macroscopically, the tumour measuring $1.5 \mathrm{~cm} \times 1.5 \mathrm{~cm} \times 1 \mathrm{~cm}$ presented as an encapsulated nodule with cut surface which is greyish white.

Microscopic description [Figure 1] of sections of left breast lump excision shows tubular adenoma. No malignancy seen. She had an uneventful postoperative course. She is currently doing well some 2 months after surgery.

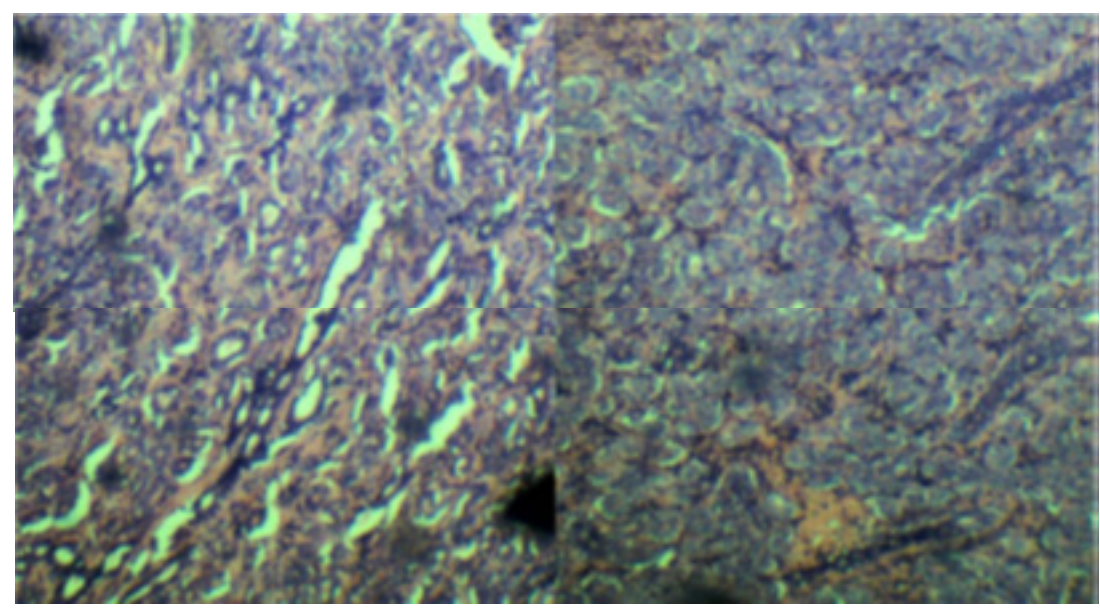

Figure 1: H\&E stain slides showing glandular proliferation with pattern resemblance to tubular adenosis. There are round or oval glandular structures and a single layer of epithelium supported by a layer of myoepithelial cells with some amount of secretion present in the glandular lumens.

\section{Discussion}

Breast tubular adenoma is a rare benign tumour and the few reported cases in literature are mainly in young women [5] and have not been associated with oral contraceptive treatment or pregnancy. In $90 \%$ of the cases, these tumors are found in patients younger than 40 years old [7]. Postmenopausal women with breast tubular adenoma are very rare $[2,5,10]$. The incidence of breast tubular adenoma varies from $0.13 \%$ to $1.7 \%$ [1,2]. However, recent 2 series by Sengupta et al $[6,11]$ showed higher incidences, $2.9 \%$ and $2.83 \%$, over periods of 3 and 10 years, respectively $[6,11]$.

Based on the classification proposed by Hertel et al [8] breast adenomas are subdivided into true adenomas, nipple adenomas and fibroadenomas [8]. True adenomas are further subclassified as tubular, lactating, apocrine, ductal, and pleomorphic adenomas [12]. Among these, lactating and tubular adenomas are the most commonly reported true adenomas in clinical practice, with both occurring during the reproductive age [13]. Tubular adenomas that occur during physiological conditions such as pregnancy, lactation, or with OCPs use have been called lactating adenomas.

Tubular adenoma differs microscopically from fibroadenoma in its histologic and ultrastructural features. Tubular adenomas are characterized by a homogeneously tightly packed tubular or acinar epithelial component and sparse connective tissue, while fibroadenomas present abundant stroma and the epithelial components are characterized by large ducts. Maiorano and Albrizio [14] studied 10 cases of tubular adenomas and 6 cases of fibroadenomas in order to investigate possible relationships between these 2 benign tumours. They found that the morphological characteristics of tubular adenoma closely resemble in some areas of the tumors those of fibroadenoma and they suggested that the two tumors may are histologically related with predominant stromal component in fibroadenomas and exuberant ductular component in tubular adenomas as has been described earlier [14]. The presence of combined tubular adenoma and fibroadenoma accounts for $4 \%$ of all benign lesions and about $11 \%$ of breast adenomas $[15,16]$.

Clinically, tubular adenoma may be asymptomatic, and it may be detected occasionally during a screening program (screening mammography) or during a physical examination as a palpable mass. Mammography and ultrasound commonly show non calcified nodules that vary in size; microcalcifications are occasionally described in postmenopausal women [16]. Due to difficulty differentiating tubular adenoma from malignant breast cancer by clinical and radiological examination [17], excision biopsy or core biopsy before surgical excision is usually needed for precise diagnosis. In our reported case patient was in the reproductive age group and requested for the excision biopsy despite the small benign nature of her breast adenoma to establish the histological variance. Very rare cases of in situ or invasive cancers have been 
reported to develop in tubular breast adenomas [1].

\section{Conclusion}

Breast Tubular adenomas are rare benign epithelial tumour commonly found in young women of reproductive age. Preoperative diagnostic challenge is mainly due to the fact that most cases have the similar clinical findings and imaging features as fibroadenomas. Surgical excision is only necessary to ascertain a definitive diagnosis since it not associated with an increased risk of breast cancer development.

\section{References}

1. Tavassoli FA, Devilee P (2003) Pathology and genetics of tumors of the breast and female genital organs. World Health Organization Classification of Tumors IARC Tumors of the Breast, France, pp: 9-112.

2. Salemis NS, Gemenetzis G, Karagkiouzis G, Seretis C, Sapounas K, et al. (2012) Tubular adenoma of the breast: a rare presentation and review of the literature. J Clin Med Res 4(1): 64-67.

3. Persaud V, Talerman A, Jordan R (1968) Pure adenoma of the breast. Arch Pathol 86(5): 481-483.

4. Moross T, Lang AP, Mahoney L (1983) Tubular adenoma of breast. Arch Pathol Lab Med 107(2): 84-86.

5. Rovera F, Ferrari A, Carcano G, Dionigi G, Cinquepalmi L, et al. Tubular adenoma of the breast in an 84-year-old woman: report of a case simulating breast cancer. Breast J 12(3): 257-259.

6. Sengupta S, Pal S, Biswas BK, Bose K, Phukan JP, et al. (2015) Evaluation of clinico-radio-pathological features of tubular adenoma of breast: a study of ten cases with histopathological differential diagnosis. Iranian Journal of Pathology 10(1): 17-22.
7. Irshad A, Ackerman SJ, Pope TL, Moses CK, Rumboldt T, et al. (2008) Rare breast lesions: correlation of imaging and histologic features with who classification. Radiographics 28(9): 1399-1414.

8. Hertel BF, Zaloudek C, Kempson RL (1976) Breast adenomas. Cancer 37: 2891-2905.

9. Tavassoli FA, Benign L (1999) In: Pathology of the breast ( $2^{\text {nd }}$ edn), Stamford Conn: Appleton \& Lange, USA, pp: 115-204.

10. Zuhair AR, Maron AR (2014) Tubular adenoma of the breast: a case report. Case Reports in Clinical Medicine 3: 323-326.

11. Sengupta S, Pal S, Biswas BK, Phukan JP, Sinha A, et al. (2014) Preoperative diagnosis of tubular adenoma of breast: 10 years of experience. $\mathrm{N}$ Am J Med Sci 6(5): 219-223.

12. Silverberg SG, Masood S (1997) The breast. In: Principles and practice of surgical pathology and cytopathology, Silverberg SG, DeLellis RA, Frable WJ (Eds.), Churchill-Livingstone Inc, (3 $3^{\text {rd }}$ edn), New York, USA, pp:575673.

13. Guray M, Sahin AA (2006) Benign breast diseases: classification, diagnosis, and management. Oncologist 11(5): 435-449.

14. Maiorano E, Albrizio M (1995) Tubular adenoma of the breast: an immunohistochemical study of ten cases. Pathol Res Pract 191(12): 12221230.

15. Bjerregaard B, Kungu A (1992) Benign breast lesions in kenya: a histological study. East Africa Medical Journal 69(5): 231-235.

16. Stavros TA, Thickman D, Rapp CL, Dennis MA, Parker SH, et al. (1995) Solid breast nodules: use of sonography to distinguish between benign and malignant lesions. Radiology 196(1): 123-134.

17. Salemis NS, Gemenetzis G, Karagkiouzis G, Seretis C, Sapounas K, et al. (2012) Tubular adenoma of the breast: a rare presentation and review of the literature. J Clin Med Res 4(1): 64-67. 